
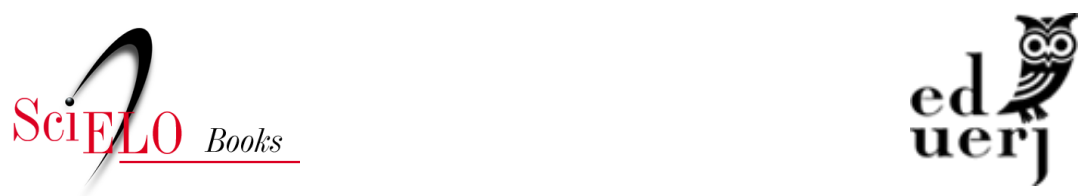

\title{
Capitulo 7 - Enfrentamento das carências de micronutrientes no Brasil: reflexões sobre as estratégiaS no âmbito da Atenção Básica
}

Kelly Poliany de Souza Alves

\section{SciELO Books / SciELO Livros / SciELO Libros}

ALVES, K. P. S. Enfrentamento das carências de micronutrientes no Brasil: reflexões sobre as estratégiaS no âmbito da Atenção Básica. In.: SILVA, A. C. F., MOTTA, A. L. B., and CASEMIRO, J. P., eds. Alimentação e nutrição na atenção básica: reflexões cotidianas e contribuições para prática do cuidado [onine]. Rio de Janeiro: EDUERJ, 2021, pp 149-170. ISBN: 978-65-87949-11-6. https://doi.org/10.7476/9786587949116.0008.

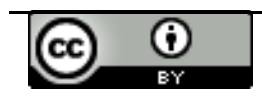

All the contents of this work, except where otherwise noted, is licensed under a Creative Commons Attribution 4.0 International license.

Todo o conteúdo deste trabalho, exceto quando houver ressalva, é publicado sob a licença Creative Commons Atribição 4.0.

Todo el contenido de esta obra, excepto donde se indique lo contrario, está bajo licencia de la licencia Creative Commons Reconocimento 4.0. 


\section{Capitulo 7 \\ Enfrentamento das carências de micronutrientes no Brasil: reflexóes sobre as estratégias no âmbito da Atençáo Básica}

Kelly Poliany de Souza Alves

A situação alimentar e nutricional da população brasileira vem passando, nas últimas décadas, por grandes mudanças que se mostram relacionadas a transformaçóes sociais, econômicas e culturais, e são observadas em inquéritos populacionais realizados a partir da década de 1970 . O rápido declínio da prevalência de desnutrição em crianças e elevação, num ritmo mais acelerado, do predomínio de sobrepeso/obesidade em adultos caracterizam a chamada transição nutricional (Batista Filho e Rissin, 2003).

No mesmo contexto, as carências de micronutrientes (vitaminas e minerais) também são identificadas como problemas no complexo quadro alimentar e nutricional dos brasileiros, gerando a adoção de medidas para seu enfrentamento desde a segunda metade do século XX (Silva, 1995; Brasil, 2008; Santos, 2002; Ramalho, Flores e Saunders, 2002; Jordão, Bernardi e Barros Filho, 2009). Mais recentemente, a nova Política Nacional de Alimentação e Nutrição (PNAN) (Brasil, 2012a, pp. 28-9) indicou entre as prioridades da atenção nutricional no Sistema Único de Saúde (SUS) as ações de prevenção e tratamento das carências nutricionais, destacando a responsabilidade da Atenção Básica na execução de açóes de prevenção.

Este capítulo tem como objetivo refletir sobre as estratégias de enfrentamento dessas carências alimentares empreendidas pelo 
Ministério da Saúde no Brasil, buscando problematizar o papel dos serviços de Atenção Básica nesse contexto, a partir da perspectiva dos cuidados em alimentação e nutrição como parte da atenção integral à saúde e da contribuição destes para a promoção da Segurança Alimentar e Nutricional.

\section{As carências de micronutrientes e as estratégias de enfrentamento}

São consideradas como principais carências de micronutrientes no Brasil as deficiências de iodo, de ferro e de vitamina A (Brasil, 2010).

A carência de iodo interfere no adequado funcionamento da glândula tireoide, que, ao ficar deficiente, apresenta as seguintes expressóes mais graves: o cretinismo (retardo mental grave e irreversível) e o bócio (hipertrofia da glândula tireoide). Além disso, está relacionada a anomalias congênitas, altas taxas de natimortos e nascimento de crianças com baixo peso, aumento do risco de abortos e mortalidade materna. Todos esses resultados são causados pela ingestão inadequada do referido mineral na dieta (Brasil, 2008).

A estratégia adotada no Brasil para seu enfrentamento foi a obrigatoriedade da iodação do sal de consumo humano a partir da década de 1950 . Desde então, vem sendo registrada uma significativa redução nas prevalências de bócio no país: 20,7\% em 1955, 14,1\% em 1974, 1,3\% em 1984 e 1,4\% em 2000. Em 2005, foi criado o Programa Nacional para Prevenção e Controle dos Distúrbios por Deficiência de Iodo (Pró-Iodo), visando ao aperfeiçoamento das açóes de prevenção e controle para evitar a reincidência desse problema (Brasil, 2008).

De acordo com a Pesquisa Nacional para Avaliação do Impacto da Iodação do Sal (PNAISAL), o objetivo de eliminar a deficiência de iodo no Brasil foi alcançado, uma vez que, em nenhum dos estados da federação ou no Distrito Federal, a proporção de crianças 
com deficiência grave chegou ao ponto de corte definido pela OMS para indicar a presença de problema de saúde pública decorrente da carência desse mineral (UFPEL; FURG, 2016).

Diante disso, este capítulo aprofundará a discussão sobre o enfrentamento das deficiências de ferro e de vitamina $A$ em virtude da permanência da sua magnitude no Brasil.

As estratégias de suplementação profilática e as açôes educativas relacionadas a hipovitaminose A e anemia ferropriva começaram a ser implementadas no Brasil nas décadas de 1970 e 1980, nas regiôes mais carentes do país, junto aos programas de suplementação alimentar para combate à desnutrição materno-infantil implementados nos serviços de saúde pública (Brasil, 1986).

Naquela conjuntura, a saúde ainda não era reconhecida como direito de todos e sua perspectiva enquanto "ausência de doenças" gerou modos de organizar os serviços e as práticas em saúde, tornando-os restritos ao atendimento de alguns grupos populacionais prioritários dos programas coordenados pelo Ministério da Saúde, relacionados à prevenção e tratamento de doenças específicas. Com a institucionalização do SUS, a descentralização e a municipalização dos serviços de saúde, o lócus de implementação das estratégias de prevenção e controle da anemia ferropriva e da deficiência de vitamina A passou a ser os serviços que conhecemos hoje como Atenção Básica (Silva, 1995; Paim, 2008).

A anemia por deficiência de ferro (anemia ferropriva) é a carência nutricional de maior magnitude no mundo, afeta países desenvolvidos e em desenvolvimento e tem como principais grupos de risco as crianças nos dois primeiros anos de vida e as gestantes fases da vida em que há aumento das necessidades desse mineral no organismo. Mesmo com a ausência de estudos nacionais, estudos locais acerca da anemia revelaram que ela poderia estar se agravando, sendo considerada a carência nutricional mais prevalente no Brasil (Brasil, 2010; Santos, 2002b; Lira e Ferreira, 2007; Jordão, Bernardi e Barros Filho, 2009; Vieira e Ferreira, 2010). 
$\mathrm{O}$ aporte inadequado de ferro da dieta e a baixa biodisponibilidade do mineral predominam como fatores etiológicos mais relevantes da anemia ferropriva. Além destes, relacionam-se ao seu desenvolvimento as doenças infecciosas e parasitárias, destacando-se as ancilostomíases, a esquistossomose e a malária. Entretanto, estudos revelam que, ao contrário do que ocorre com a anemia, a prevalência das parasitoses no país está em declínio e, por isso, tem pouca relevância na etiologia da anemia, sendo preponderantes as causas de origem dietética (Brasil, 2010; Lira e Ferreira, 2007).

As estratégias adotadas no Brasil para prevençáo da anemia ferropriva aliam: suplementaçáo medicamentosa profilática com sais de ferro em grupos de risco; açóes educativas para aumentar e melhorar o consumo de alimentos fontes de ferro; e fortificação de alimentos básicos largamente consumidos pela população (quadro 1).

A deficiência de vitamina A (DVA) apresenta prevalência particularmente alta em regióes como Ásia, África e América Latina - ainda que os inquéritos nacionais sejam escassos -, acometendo, principalmente, crianças em idade pré-escolar, recém-nascidos, mulheres grávidas e nutrizes, considerados como o grupo clássico de risco. No Brasil, estudos locais a identificaram como um problema de saúde pública na regiáo Nordeste e em algumas áreas das regióes Norte e Sudeste, afetando especialmente crianças menores de cinco anos de idade (Brasil, 2010; Ramalho, Flores e Saunders, 2002; Santos, 2002; Santos et al., 1996).

Assim como a deficiência de ferro, o principal fator etiológico da DVA é sua ingestão inadequada na dieta, mas também pode estar relacionada a parasitoses intestinais (sobretudo a giardíase, a ascaridíase e a estrongiloidíase), diarreia aguda, ressecçōes intestinais e doenças pancreáticas. No caso das crianças, seu risco potencial para o desenvolvimento da DVA aumenta quando a tríade está presente: DVA materna resultando em baixas concentrações de vitamina $A$ no leite materno; ingestão inadequada de vitamina A durante $\mathrm{e}$ 
após o desmame e a presença simultânea de doenças prevalentes na infância, principalmente as infecciosas, como a diarreia (Brasil, 2010; Diniz e Santos, 2007).

As estratégias adotadas no Brasil para prevenção da hipovitaminose A sáo a suplementaçáo medicamentosa profilática com megadoses da vitamina em grupos de risco e açôes educativas para aumentar e melhorar o consumo de alimentos fontes de vitamina $\mathrm{A}$ ou carotenoides pró-vitamina A, como o betacaroteno (quadro 1).

A II Pesquisa Nacional de Demografia e Saúde (PNDS) foi o primeiro inquérito, em nível nacional, que avaliou a prevalência de deficiência de ferro e vitamina $\mathrm{A}$ em mulheres em idade fértil e crianças menores de cinco anos. De acordo com os padróes estabelecidos pela Organização Mundial de Saúde para essas duas carências nutricionais, a II PNDS encontrou prevalências que as classificaram como problemas de saúde pública no Brasil, com variações entre as regiōes do país (Brasil, 2009a).

Foi com base nos resultados da II PNDS que o Ministério da Saúde justificou a ampliação da abrangência do Programa Nacional de Suplementação de Vitamina A para todas as regiôes do país a partir de 2012 e revisou as estratégias de prevençáo da anemia ferropriva, atualizando, em 2013, as condutas do Programa Nacional de Suplementaçáo de Ferro e lançando, em 2014, a Estratégia de fortificação da alimentação infantil com micronutrientes em pó (NutriSUS) (quadro 1).

No entanto, o estudo de Pereira (2018) demonstra a inadequação do método utilizado na II PNDS para diagnóstico das deficiências de ferro e vitamina $\mathrm{A}$, o que pôe em dúvida a principal referência utilizada para justificar os programas de suplementação profilática em vigor no Brasil. 
154 Alimentação e nutrição na Atenção Básica

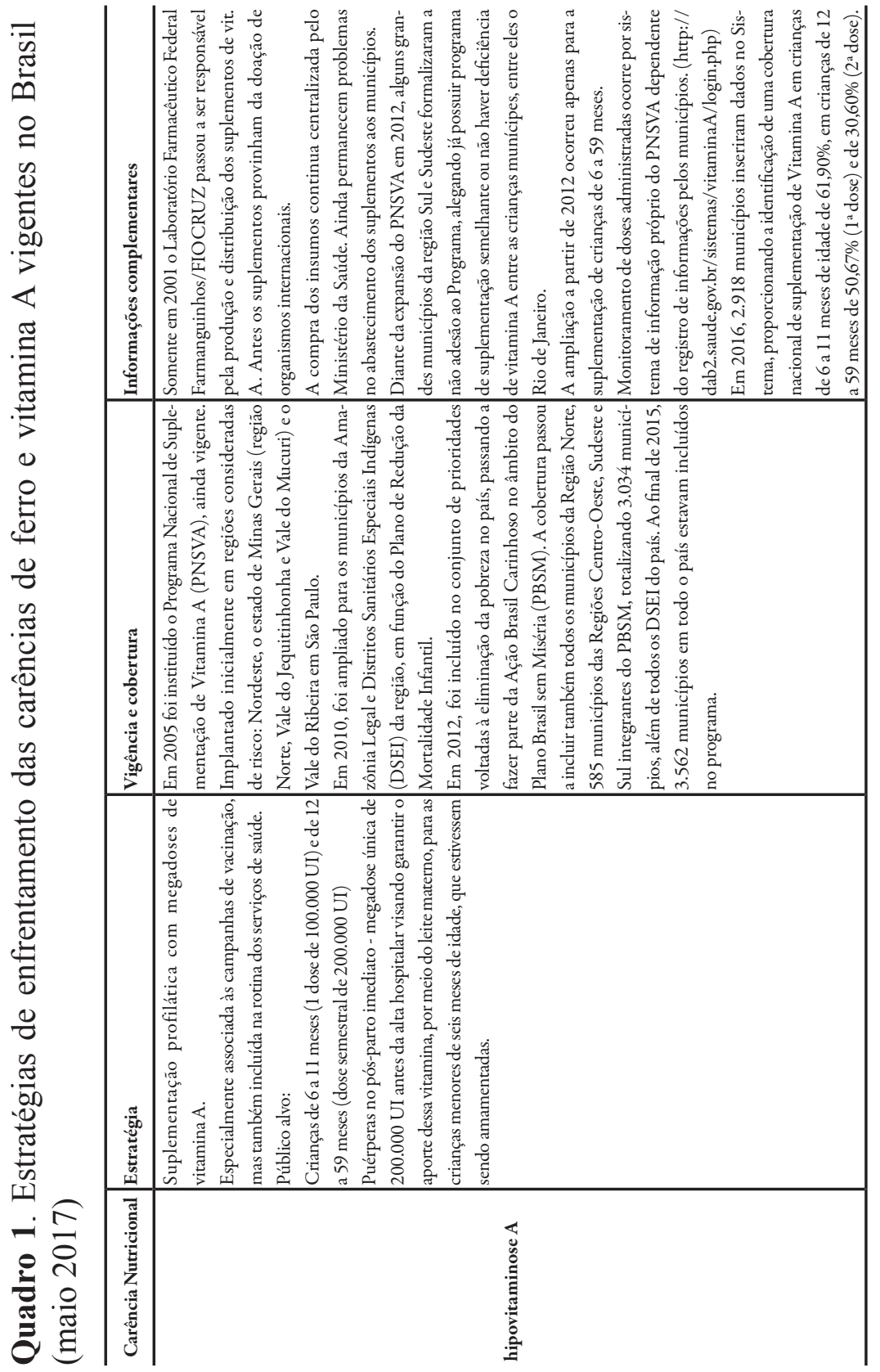




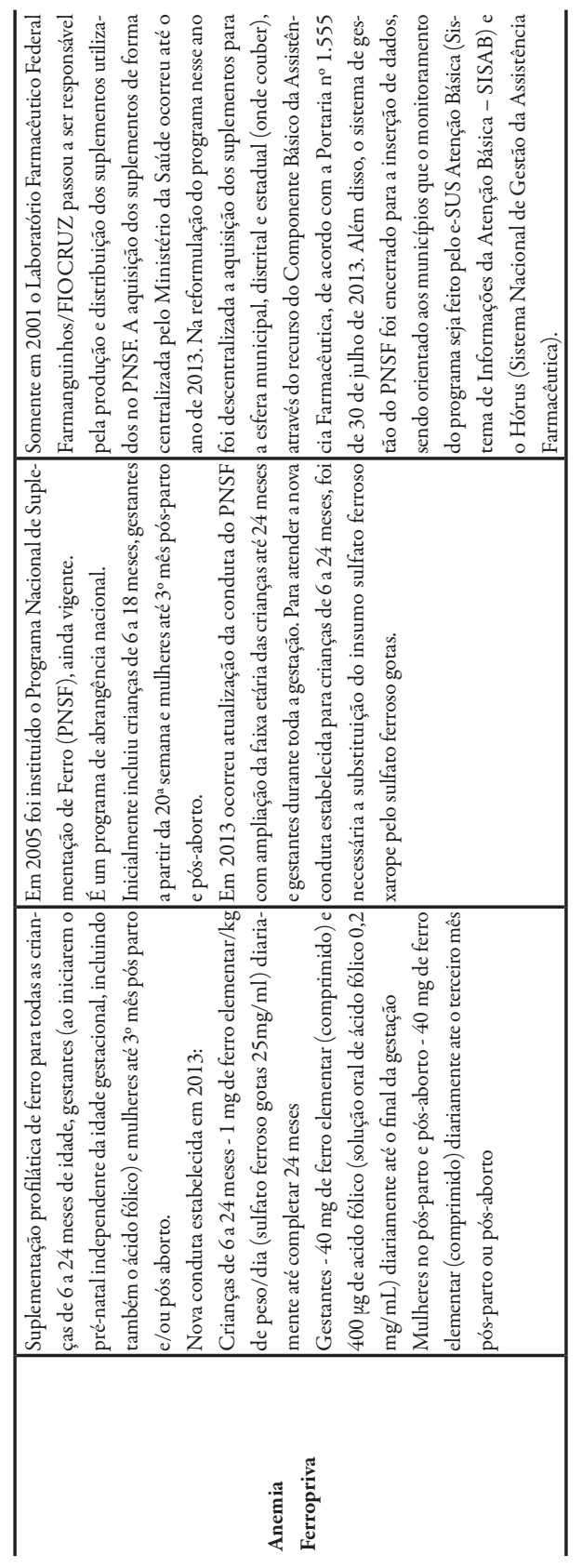


156 Alimentação e nutrição na Atenção Básica

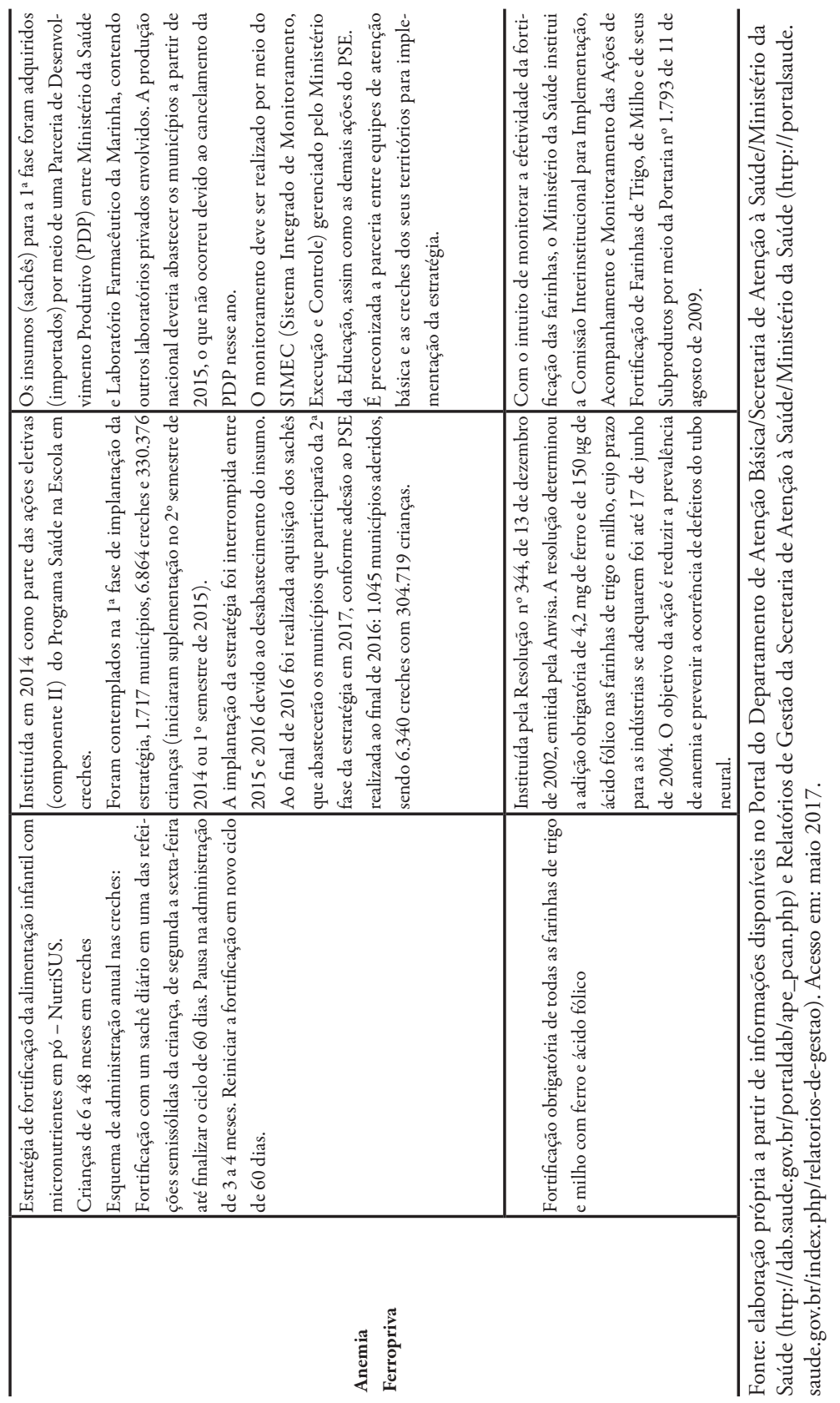


Ao longo de todo esse período (cerca de trinta anos), há falhas de cobertura e escassez de monitoramento e avaliação da implementação e impacto das estratégias de enfrentamento das carências de micronutrientes no Brasil, ao passo que a manutenção ou aumento das prevalências das carências nutricionais específicas sugerem que os esforços empreendidos sejam ineficazes ou insuficientes para o enfrentamento desses problemas (Brasil, 2009a; Brasil, 2010; Martins et al., 2007a; Martins et al., 2007b; Rodrigues e Roncada, 2010; Carvalho et al., 2009; Santos, 2002a; Santos, 2002b).

A predominância das carências nutricionais de ferro e vitamina A apresenta como principal fator etiológico a ingestâo inadequada de alimentos que sejam boas fontes desses micronutrientes. Desse modo, a baixa prevalência de aleitamento materno exclusivo até o sexto mês de vida e a alimentação complementar inadequada em crianças menores de dois anos são fatores de risco de importante relevância. Por isso, as açôes de promoção desses dois fatores - aleitamento materno e alimentaçáo complementar -, ao lado da introdução dos alimentos complementares em tempo oportuno e de qualidade, devem ser as primeiras medidas para prevenção dessas carências nutricionais.

O cuidado no pré-natal e nos primeiros meses de vida é oportuno para identificar os riscos para o desmame precoce e estabelecer medidas de intervenção, pois são períodos cruciais para as mulheres construírem sua compreensão sobre a alimentação infantil e nos quais enfrentam muitas dificuldades para amamentar, como as pressôes sociais para a introdução precoce de outros alimentos ou mesmo a substituição completa do AM, entre outras. Nesse sentido, iniciativas em diversos países foram desenvolvidas ainda na década de 1990 para explorar o potencial dos serviços de atenção primária à saúde (Atenção Básica), considerando que estes são os principais responsáveis pelo acompanhamento das gestantes durante o pré-natal e dos bebês na puericultura (Oliveira e Camacho, 2002). 
No Brasil, diante da expansão de cobertura da $\mathrm{AB}$ a partir do final da década de 1990, sobretudo pela implantação da Estratégia Saúde da Família (ESF) como modelo prioritário, e consequentemente do aumento de cobertura da assistência às gestantes e crianças, entende-se que a qualificação da promoção do AM e da ACS nessa rede de serviços se apresenta como ação estratégica para incentivo e apoio a práticas alimentares saudáveis para as crianças menores de dois anos. Frente a isso, experiências têm sido desenvolvidas pelo Ministério da Saúde em parceria com Secretarias Estaduais e Municipais de Saúde e com a Rede Internacional em Defesa do Direito de Amamentar (IBFAN).

Inicialmente, de formas separadas, as estratégias nacionais direcionadas à $\mathrm{AB}$ para promoção do AM (Rede Amamenta BrasilRAB, lançada em 2008) e da alimentação complementar saudável (Estratégia Nacional de Promoção da Alimentação Complementar Saudável - ENPACS, lançada em 2009) foram baseadas nos pressupostos da educação crítico-reflexiva e alinhadas à Política Nacional de Educação Permanente em Saúde. Ambas promoveram a formação de tutores que deveriam ser multiplicadores nas Unidades Básicas de Saúde (UBS), induzindo as equipes de saúde a discutir seu processo de trabalho frente às questóes relativas à promoção do AM e ACS e, ao expor suas dificuldades e acertos, buscar soluçóes a partir de sua realidade (Venâncio et al., 2013; Baldissera, Issler e Giuliani, 2016).

Estudos locais evidenciaram o potencial dessas estratégias em contribuir para a melhoria da alimentação infantil, sugerindo a relevância de investimentos institucionais nesse tipo de estratégia (Passanha et al., 2013; Venâncio et al., 2013; Baldissera, Issler e Giugliani, 2016).

Uma vez que a RAB e a ENPACS previam açóes complementares e atingiam o mesmo público-alvo (profissionais das equipes de AB, mães, crianças e suas famílias), o Ministério da Saúde construiu a fusão das duas e lançou, em 2012, a Estratégia Amamenta e Alimenta Brasil (EAAB) - plano nacional para promoção do alei- 
tamento materno e alimentação complementar saudável no SUS. A nova estratégia manteve os princípios e bases metodológicas das anteriores (Brasil, 2013).

No entanto, frente ao número e capilaridade de equipes de Atenção Básica no país, o alcance dessa estratégia ainda é pequeno e lento (Brasil, 2013; Brasil, 2016; Brasil, 2017b). É fundamental a priorização de investimentos, das três esferas de gestão do SUS, para ampliação da EAAB, a fim de que as açóes desenvolvidas do âmbito da $\mathrm{AB}$ em prol do $\mathrm{AM}$ e da ACS possam contribuir para melhoria do padrão alimentar das crianças brasileiras. Também é necessário investir em um processo permanente de monitoramento e avaliação que permita o aprimoramento contínuo e a sustentabilidade da estratégia.

\section{Para (re)pensar o enfrentamento das carências de micronutrientes}

Embora seja indicado que os serviços de Atenção Básica (AB) devam organizar seu processo de trabalho em acordo com as necessidades da população que está sob sua responsabilidade, os trabalhadores convivem com a tensão entre "dar conta" das ações preconizadas pelos programas estabelecidos pelo Ministério da Saúde (muitas vezes de forma verticalizada), atender a demanda espontânea da população por açóes assistenciais e desenvolver também ações de promoção da saúde (Alves, 2010).

Nesse contexto, é necessário problematizar que a perpetuação das estratégias de enfrentamento das carências de ferro e vitamina A, centradas apenas na administração de suplementos profiláticos e/ou em ações educativas tradicionais (que têm como foco apenas os aspectos biológicos dos alimentos e visam à mudança de comportamento alimentar, como se as escolhas alimentares e suas consequências para a saúde fossem determinadas apenas pela falta de informaçóes), podem comprometer a atenção integral à 
saúde na $A B$, pois produzem práticas pontuais desarticuladas das necessidades de saúde das pessoas e das demais ofertas de cuidado nos serviços de saúde.

Conforme explica Mattos (2001), a integralidade como modo de organizar os serviços e as práticas em saúde requer que as equipes das unidades de saúde passem a pensar suas práticas, sobretudo, a partir do horizonte da população que atendem e das suas necessidades. A diretriz de organização da atenção nutricional da PNAN converge para esse sentido da integralidade ao sinalizar importantes aspectos para uma apreensão ampliada das necessidades da população: o reconhecimento dos indivíduos enquanto membros de famílias e comunidades, "sujeitos coletivos" que possuem suas formas próprias de organização e necessidades distintas, assim como apresentam diferentes respostas a fatores que lhes possam afetar; a necessidade de considerar as especificidades de diferentes grupos populacionais, povos e comunidades tradicionais, bem como as diferenças de gênero e de cada fase do curso da vida (Brasil, 2012a).

Igualmente nesse intuito, a PNAN indica, na sua primeira diretriz, a importância de incluir no processo de territorialização, realizado pelas equipes de Atenção Básica (AB), a identificação dos espaços de produção, comercialização e distribuição de alimentos, além dos costumes e tradições alimentares locais, entre outras características do território onde vive a população adstrita, que possam relacionar-se aos seus hábitos alimentares e ao estado nutricional (Brasil, 2012a, p. 27).

Assim, orienta-se que o processo de organização e gestão dos cuidados relativos à alimentação e nutrição na rede de atenção à saúde deverá ser iniciado pelo diagnóstico da situação alimentar e nutricional da população adstrita aos serviços e equipes de AB. Entretanto, esse diagnóstico deve ir além da utilização das informaçóes epidemiológicas clássicas da vigilância alimentar e nutricional (VAN), relacionadas ao estado nutricional e ao consumo alimentar. Ou seja, somente os dados registrados nos sistemas de informação em saúde, como o Sistema de Vigilância Alimentar e Nutricional 
(SISVAN) e o Sistema de Informação da $\mathrm{AB}$ (SISAB), não são capazes de captar as diversas dimensões da alimentação e nutrição nos territórios e nas vidas das pessoas.

A VAN, no acompanhamento pré-natal e na puericultura, em especial a análise de marcadores de consumo alimentar, assim como o reconhecimento das características e dinâmicas do ambiente alimentar (no território, nas famílias), contribuirá para identificação de práticas alimentares e seus determinantes que possam relacionar-se ao desenvolvimento de carências de micronutrientes, subsidiando as equipes de $\mathrm{AB}$ para a melhor análise e tomada de decisão quanto às ofertas de cuidado mais oportunas para a população sob sua responsabilidade. Por exemplo: a realização de exames bioquímicos para complementar o diagnóstico de carências; a prescrição do tratamento medicamentoso quando necessário; a realização de orientaçôes alimentares contextualizadas; a educação alimentar e nutricional (EAN) com metodologias que potencializem a participação social e valorizem o saber popular; e a articulação intersetorial para a promoção da alimentaçấo adequada e saudável nas dimensões de incentivo, apoio e proteção.

A PNAN indica ainda que a Atenção Nutricional, no âmbito da $A B$,

deverá dar respostas às demandas e necessidades de saúde do seu território, considerando as de maior frequência e relevância e observando critérios de risco e vulnerabilidade. Diante do atual quadro epidemiológico do país, são prioritárias as açóes preventivas e de tratamento da obesidade, da desnutrição, das carências nutricionais específicas e de doenças crônicas não transmissíveis, relacionadas à alimentação e nutrição (Brasil, 2012b, p. 28).

Aqui, observamos outro sentido da integralidade apontado por Mattos (2001), aquele que diz respeito às configuraçôes de certas políticas específicas, desenhadas para dar respostas a um 
determinado problema de saúde, ou aos problemas de saúde que afligem um certo grupo populacional. Nesse sentido, o autor aponta que a integralidade deve estar expressa nas respostas do governo aos problemas de saúde pública por meio da incorporação tanto de possibilidades de prevençáo como assistenciais.

Por outro lado, a partir dessa orientação para a organização da Atenção Nutricional nos serviços de saúde, baseada em "frequência e relevância" e "critérios de risco e vulnerabilidade", a partir de um quadro epidemiológico, corre-se o risco de rompimento da integralidade, uma vez que na definição de prioridades em torno dos piores indicadores pode-se restringir a percepção das necessidades de saúde ao invés de ampliá-las. E, dessa forma, realizar açóes sob uma perspectiva reducionista de enfrentamento do problema de saúde (Mattos, 2001), por exemplo: no caso dos agravos à saúde relativos à alimentação e nutrição, reduzir a questão apenas à garantia do aporte adequado de calorias e/ou nutrientes sem considerar questóes socioeconômicas, dinâmica intrafamiliar de distribuição dos alimentos, a cultura alimentar, entre outros aspectos.

Estudos locais que avaliaram o programa de suplementação de vitamina A revelam que essa perspectiva reducionista está presente, pois predomina o foco apenas na distribuição das cápsulas de megadoses, por vezes identificadas como vacinas. Por consequência, o monitoramento realizado diz respeito apenas ao controle estatístico de produção (doses administradas), ao lado da ausência de estratégias de promoção do acesso e consumo de uma alimentação adequada e saudável, como o estabelecimento de vínculos de colaboração com outros programas e políticas públicas. Além disso, as açôes educativas não são executadas ou sofrem interrupçôes, ocorrendo de forma temporária e sem avaliação, o que se deve principalmente ao fato destas não fazerem parte de um contexto mais amplo de promoção da saúde (Carvalho et al., 2009; Almeida et al., 2010; Martins et al., 2007a; Rodrigues e Roncada, 2010). 
No caso do programa de suplementação de ferro, estudos locais apontam diversas falhas em sua implementaçáo, como a irregularidade na disponibilização do suplemento nos serviços de saúde, baixa adesão e descontinuidade do uso deste (Motta, Domingues e Colpo, 2010; Cembranel, 2012; Nagahama, 2014; Oliveira, Nascimento e Moreira, 2014; Stubalch et al., 2014). Isso pode ser agravado frente às últimas mudanças referentes à aquisição e distribuição dos insumos (suplementos medicamentosos) citadas no quadro 1.

Como indicamos anteriormente, a baixa prevalência de aleitamento materno exclusivo até o sexto mês de vida e a alimentação complementar inadequada em crianças menores de dois anos são fatores de risco de importante relevância para as deficiências de ferro e vitamina A. Por isso, promover o aleitamento materno exclusivo ao lado da introduçáo de alimentos complementares de qualidade e em tempo oportuno devem ser as primeiras medidas para prevenção dessas carências nutricionais. No entanto, é preciso atentar para garantir cuidado adequado também às crianças em aleitamento artificial e em aleitamento misto (materno e artificial), com atenção qualificada às suas mães e famílias. Esse público está muito suscetível às práticas inadequadas que podem causar sérios danos à saúde das crianças como desenvolvimento precoce de alergias e deficiências nutricionais.

É fato que, embora haja grandes avanços nos indicadores relacionados ao aleitamento materno (AM) no Brasil, estes ainda estáo longe do ideal, ao mesmo tempo em que cresce a preocupação com a introdução precoce e inadequada da alimentação complementar. Em 2008, foi identificada, nas capitais do país, uma mediana de AM exclusivo de 54 dias, quando o recomendado é de 180 dias (Brasil, 2009b). A II PNDS identificou elevada frequência de crianças menores de dois anos que consumiam biscoito, bolacha ou bolo $(60,8 \%)$ e ingeriam refrigerante ou suco artificial $(32,3 \%)$, e, por outro lado, a baixa frequência de crianças consumindo diariamente frutas, verduras e carnes (Brasil, 2009a). 
Junto à defesa militante pelo aleitamento materno exclusivo parece ter se tornado um tabu falar sobre aleitamento artificial, como se isso fosse causar um desestímulo ao que se preconiza como a melhor alimentação para os bebês até o sexto mês de vida. A ausência de oferta de informaçóes e qualificação técnica adequada dos profissionais de saúde sobre o aleitamento artificial pelos órgãos gestores do SUS e pelas instituiçóes formadoras abre espaço para que as indústrias produtoras de substitutos do leite materno assumam esse papel.

A indústria de alimentos e a indústria farmacêutica produzem em todo o mundo grande variedade de fórmulas nutricionais pediátricas utilizadas como substitutos do leite materno - por exemplo, suplementos alimentares -, como opçóes para dietas enterais e tratamento para alergias alimentares. Essas fórmulas, quando prescritas e utilizadas com base em critérios estabelecidos por protocolos clínicos e diretrizes terapêuticas, podem contribuir para a recuperação ou manutençáo do estado de saúde de crianças que apresentam condiçóes agudas ou crônicas que repercutem negativamente sobre seu estado nutricional e seu desenvolvimento. No entanto, as práticas de prescrição inadequada e de estímulo ao consumo desnecessário de tais fórmulas podem acarretar danos à saúde das crianças, à situação de vida de suas famílias e ao Sistema de Saúde.

Essas práticas têm sido associadas a estratégias de marketing e lobby das indústrias voltadas aos profissionais prescritores das fórmulas nutricionais pediátricas, como médicos e nutricionistas. Essas estratégias incluem: financiamento de pesquisas e disseminação de evidências científicas sobre a eficácia de seus produtos; visitas para divulgação dos produtos; financiamento da participação de profissionais em eventos; patrocínio de eventos, entidades de classe e instituiçōes formadoras, entre outras. Essa atuação influencia a conduta e consequentemente as prescriçôes dos profissionais de saúde, acarretando, em alguns casos, diagnósticos equivocados, prescriçóes desnecessárias ou indutivas do consumo de determinada marca. 
Um dos efeitos da atuação da indústria é a criação de uma rede de profissionais e instituiçôes em conflito que tem amplos efeitos sobre: periódicos científicos, formação de novos profissionais, definição de diretrizes de atuação de especialistas, veiculação de informaçóes conflituosas na mídia, gastos do Sistema de Saúde para compra desses insumos e até na formulação de políticas públicas.

Diante do exposto, ressaltamos que não bastam apenas medidas na dimensão de incentivo às práticas alimentares adequadas e saudáveis voltadas às gestantes, nutrizes e crianças. Embora seja importante difundir informaçôes adequadas e possibilitar práticas educativas que motivem os indivíduos para a adoção de práticas saudáveis, é fundamental avançar nos demais âmbitos da promoção da alimentação adequada e saudável.

A dimensão do apoio inclui iniciativas para tornar mais factível a adesão a práticas saudáveis por indivíduos e coletividades informados e motivados. Nesse caso, destacamos as medidas de apoio às mães e demais cuidadores das crianças para que consigam ofertar a elas a melhor alimentação. Por exemplo, a garantia da licença maternidade até o sexto mês de vida do bebê, a extensão da licença paternidade, a garantia de vagas em creches com oferta de boa alimentação, entre outras.

Tal proteção abrange também açôes para impedir que coletividades e indivíduos fiquem expostos a fatores e situaçôes que estimulem práticas não saudáveis. Aqui, podem ser incluídas ações que regulem as práticas das indústrias que produzem alimentos para o público infantil e as práticas de profissionais de saúde prescritores de alimentos infantis, entre outras medidas.

\section{Consideraçóes finais}

As estratégias em curso no Brasil, implementadas no âmbito da $A B$, são fundamentadas em evidências científicas e recomendaçôes de agências internacionais (tanto a suplementação medica- 
mentosa de ferro e vitamina A quanto a qualificação das práticas de promoção do aleitamento materno e alimentação complementar saudável). No entanto, considerando os aspectos discutidos neste texto, cabe questionar se o setor saúde está investindo atualmente a maior parte de seus recursos técnicos, políticos e financeiros nas melhores estratégias para o país. Ou se caberia o desenvolvimento de uma estratégia genuinamente brasileira, que considerasse as particularidades dos determinantes sociais de tais problemas nutricionais no país, bem como a organização do Sistema Único de Saúde e do Sistema de Segurança Alimentar e Nutricional.

Observa-se que a suplementação profilática de micronutrientes se perpetua e se expande há mais de trinta anos sem que haja monitoramento e avaliação sistemática de sua implementação e seu impacto sobre a prevalência das respectivas carências no público-alvo. Apenas o controle de compra, distribuição e administração dos suplementos não dá respostas suficientes quanto à eficácia dos programas. Os estudos locais mencionados aqui dão pistas sobre importantes problemas na execução dos programas que indicam a emergência da realização de uma avaliação com representatividade nacional e de prudência técnica e política quanto à sua continuidade e expansão.

A experiência brasileira no tocante à redução da desnutrição infantil deixa claro que a superação dos agravos relativos à alimentação e nutrição demandam muito mais do que esforços isolados do setor da saúde. A manutenção ou aumento das prevalências das carências de micronutrientes sugerem que os esforços desse setor sejam ineficazes ou insuficientes para o enfrentamento desses problemas.

Tendo em vista que a alimentação adequada e saudável está relacionada a múltiplas dimensóes sociais, econômicas, ambientais e culturais, ressalta-se que o trabalho dos profissionais da $A B$ tem possibilidades, mas também muitos limites frente ao complexo cenário de determinação das práticas alimentares. É preciso incluir o enfrentamento das carências de micronutrientes na agenda intersetorial da Política de Segurança Alimentar e Nutricional, considerando que 
estratégias protagonizadas por diferentes setores de políticas públicas são complementares e podem potencializar mudanças positivas no cenário alimentar e nutricional da população, em especial sobre a promoção do aleitamento materno e a alimentação complementar saudável, principal estratégia de prevenção das carências nutricionais específicas em crianças.

Dessa forma, o enfrentamento das carências de micronutrientes deixaria de ser o objetivo final de ações específicas do setor da saúde e passaria a ser consequência de um conjunto de estratégias intersetoriais de promoção e garantia da Segurança Alimentar e Nutricional. E a suplementação de micronutrientes passaria a ser uma ação coadjuvante no serviço de saúde, quando necessário, e não a única ou a principal ação no tocante ao enfrentamento dessas carências.

\section{Referências}

ALMEIDA, E. R. et al. "Avaliação participativa do Programa Nacional de Suplementação de Vitamina A em um município da Região Nordeste do Brasil”. Cad. Saúde Pública, v. 26, n. 5, pp. 949-60, Rio de Janeiro, maio 2010.

ALVES, K. P. S. Promoção de segurança alimentar e nutricional na estratégia saúde da família: uma aproximação a partir da escuta de diferentes atores sociais (dissertaçáo). Universidade do Estado do Rio de Janeiro, 2010.

BALDISSERA, R et al. "Efetividade da Estratégia Nacional para Alimentação Complementar Saudável na melhoria da alimentação complementar de lactentes em um município do Sul do Brasil”. Cad. Saúde Pública, v. 32, n. 9, Rio de Janeiro, set 2016.

BATISTA FILHO, M. e RISSIN, A. "A transição nutricional no Brasil: tendências regionais e temporais”. Cad. Saúde Pública, v. 19, sup. 1, pp. S181-91, Rio de Janeiro, 2003.

e BARBOSA, N. P. Alimentação e Nutrição no Brasil 1974-1984. Brasília: Ministério da Saúde/Instituto Nacional de Alimentação e Nutrição, 1984.

BRASIL. Ministério da Saúde. Manual Técnico e Operacional do Pró-Iodo: Programa Nacional para a Prevençâo e Controle dos Distúrbios por Deficiência de Iodo. Brasília: Ministério da Saúde, 2008. 
. Ministério da Saúde, Centro Brasileiro de Análise e Planejamento. Pesquisa Nacional de Demografia e Saúde da Criança e da Mulher-PNDS 2006: dimensóes do processo reprodutivo e da saúde da criança. Brasília: Ministério da Saúde, 2009a.

. Ministério da Saúde. II Pesquisa de Prevalência do Aleitamento Materno nas capitais brasileiras e Distrito Federal. Brasília: Ministério da Saúde, 2009b. . Carências de micronutrientes. 1 ed, 1. ${ }^{\mathrm{a}}$ reimp. Brasília: Ministério da Saúde, 2010.

. Boletim ENPACS. Brasília, DF, 2011.

- Politica Nacional de Alimentação e Nutrição. Brasília: Ministério da Saúde, 2012a.

. Ministério da Saúde. Secretaria de Atenção à Saúde. Relatório de Gestão da Secretaria de Atenção à Saúde-2011. Brasília: Ministério da Saúde, 2012b. . Ministério da Saúde. Secretaria de Atenção à Saúde. Portaria n. ${ }^{\circ}$ 1.920, de 5 de setembro de 2013. Institui a Estratégia Nacional para Promoçáo do Aleitamento Materno e Alimentação Complementar Saudável no Sistema Único de Saúde (SUS) - Estratégia Amamenta e Alimenta Brasil. Brasília: Ministério da Saúde, 2013.

. Ministério da Saúde. Secretaria de Atenção à Saúde. Relatório de Gestão da Secretaria de Atenção à Saúde-2015. Brasília: Ministério da Saúde, mar. 2016.

. Ministério da Saúde. Sala de Apoio a Gestão Estratégica. Redes e Programas - Atenção Básica. Disponível em: http://sage.saude.gov.br. Acesso em: mar. 2017.

CARVAlHO, A. T. et al. Análise do Programa Vitamina A Mais e do acompanhamento das condicionalidades de saúde do Programa Bolsa Família em municípios da região Nordeste do Brasil: relatório de pesquisa. Brasília: Ministério da Saúde, 2009.

CEMBRANEL, F. Avaliação do Programa Nacional de Suplementação de Ferro em crianças de seis a 18 meses atendidas em centros de saúde da rede pública de Florianópolis, Santa Catarina (dissertação). Universidade Federal de Santa Catarina, 2012.

et al. "Efetividade da suplementação de sulfato ferroso na prevenção da anemia em crianças: revisão sistemática da literatura e meta-análise”. Cad. Saúde Pública, v. 29, n. 9, pp. 1731-51, Rio de Janeiro, set. 2013

DINIZ, A. S. e SANTOS, L. M. P. "Epidemiologia da Hipovitaminose A e Xeroftalmia”. In KAC, G. et al. (orgs.). Epidemiologia nutricional [online]. Rio de Janeiro: Editora FIOCRUZ/Atheneu, 2007, pp. 325-46.

JORDÃO, R. E. et al. "Prevalência de anemia ferropriva no Brasil: uma revisão sistemática”. Rev Paul Pediatr, v. 27, n. 1, pp. 90-8, 2009. 
LIRA, P. I. C. e FERREIRA, L. O. C. "Epidemiologia da anemia ferropriva". In KAC, G. et al. (orgs.). Epidemiologia nutricional [online]. Rio de Janeiro: Editora FIOCRUZ/Atheneu, 2007, pp. 297-323.

MARTINS, M. C. et al. "Avaliaçâoo de políticas públicas de segurança alimentar e combate à fome no período 1995-2002. 3 - O Programa Nacional de Controle da Deficiência de Vitamina A". Cad. Saúde Pública, v. 23, n. 9, pp.2081-93, Rio de Janeiro, set. 2007a.

et al. "Panorama das açốes de controle da deficiência de vitamina A no Brasil". Rev. Nutr., v. 20, n. 1, pp. 5-18, Campinas, jan./fev. 2007b.

MATTOS, R. A. "Os Sentidos da Integralidade: algumas reflexões acerca de valores que merecem ser defendidos". In e PINHEIRO, R., (orgs.). Os sentidos da integralidade na atenção e no cuidado à saúde. Rio de Janeiro: UERJ, IMS: ABRASCO, 2001.

MOTTA, N. G. et al. "Impacto do Programa Nacional de Suplementação de Ferro em crianças do município de Santa Maria, RS”. Revista da AMRIGS, v. 54, n. 4, pp. 393-8, Porto Alegre, out./dez. 2010.

NAGAHAMA, D. Impacto da intervenção com suplementação de ferro semanal e orientação nutricional na ocorrência de anemia em lactentes atendidos em dois centros de saúde da cidade de Manaus - AM (tese). Universidade de São Paulo, 2004.

OLIVEIRA, T. G. et al. "O Programa Nacional de Suplementação de Ferro na Ótica dos Profissionais de Nutrição do Município de Cabedelo-PB”. Revista Brasileira de Ciências da Saúde, v. 18, n. 2, pp. 121-30, 2014.

OLIVEIRA, M. I. C. e CAMACHO, L. A. B. "Impacto das Unidades Básicas de Saúde na duração do aleitamento materno exclusivo". Rev. Bras. Epidemiol., v. 5, n. 1, 2002.

PAIM, J. S. "Modelos de Atenção à Saúde no Brasil”. In GIOVANELLA, L. (org.). Políticas e sistema de saúde no Brasil. Rio de Janeiro: Editora FIOCRUZ, 2008, pp. 547-73.

PASSANHA, A. et al. "Implantação da Rede Amamenta Brasil e prevalência de aleitamento materno exclusivo". Rev Saúde Pública, v. 47, n. 6, pp. 1141-8, 2013.

PEREIRA, A. S. Avaliação do desempenho de métodos diagnósticos de anemia e DVA em crianças menores de cinco anos (tese). Universidade do Estado do Rio de Janeiro, 2018.

RAMALHO, R. A. et al. "Hipovitaminose A no Brasil: um problema de saúde pública". Panam Salud Publica/Pan Am J Public Health, v. 12, n. 2, 2002

RODRIGUES, L. P. F. e RONCADA, M. J. "A educaçáo nutricional nos programas oficiais de prevenção da deficiência da vitamina A no Brasil”. Rev. Nutr., v. 23, n. 2, pp. 297-305, Campinas, mar./abr. 2010 
SANTOS, L. M. P. (org.). Bibliografia sobre deficiência de micronutrientes no Brasil 1990-2000: volume 1 - vitamina A. Brasília: Organização Pan-Americana da Saúde, 2002a.

(org.). Bibliografia sobre deficiência de micronutrientes no Brasil: 19902000: volume $2 b$ - anemia. Brasília: OPAS; 2002b.

et al. "Epidemiologia da carência de vitamina A no nordeste do Brasil". Bol Oficina Sanit Panam, v. 120, n. 6, pp. 525-37, 1996.

STULBACH, T. E. et al. "Eficácia do programa nacional de suplementação de ferro no controle de anemia em lactentes assistidos em centros de educaçáo infantil". Journal of Human Growth and Development, v. 24, n. 3, pp. $282-$ 8, 2014.

SILVA, A. C. "De Vargas a Itamar: políticas e programas de alimentação e nutrição". Estudos Avançados, v. 9, n. 23, pp. 87-107, 1995.

UFPEL e FURG. Pesquisa nacional para avaliação do impacto da iodação do sal (PNAISAL): Relatório Técnico Final. Pelotas, dez. 2016. Disponível em: http://189.28.128.100/dab/docs/portaldab/documentos/pnaisal_relatorio_final.pdf. Acesso em: 2019.

VENÂNCIO, S. I. et al. "Análise de implantação da Rede Amamenta Brasil: desafios e perspectivas da promoção do aleitamento materno na atenção básica”. Cad. Saúde Pública, v. 29, n. 11, pp. 2261-74, Rio de Janeiro, nov. 2013.

VIEIRA, R. C. S. e FERREIRA, H. S. "Prevalência de anemia em crianças brasileiras, segundo diferentes cenários epidemiológicos”. Rev. Nutr., v. 23, n. 3, pp. 433-44, Campinas, maio/jun. 2010.

WORLD HEALTH ORGANIZATION. Indicators for assessing Vitamin A deficiency and their application in monitoring and evaluating intervention programmes. WHO/NUT/96.10, 1996.

. Iron Deficiency Anaemia: assessment, prevention and control - A guide for programme managers. Geneva: WHO, 2001. 